Abstract THU0124 - Table 1. Summary of Patient Characteristics

\begin{tabular}{|c|c|}
\hline Patient Characteristic ( $\mathrm{N}=122$ ) & Mean $(\mathrm{SD})^{*}$ \\
\hline Duration of prior adalimumab, years & $5.1(3.0)$ \\
\hline Duration of remission, years & $2.2(2.0)$ \\
\hline \multicolumn{2}{|l|}{ Concomitant csDMARDs dose, mg } \\
\hline Methotrexate (weekly) & $13.2(5.5)$ \\
\hline Hydroxychloroquine (daily) & $228.6(75.6)$ \\
\hline Sulfasalazine (daily) & $750.0(288.7)$ \\
\hline Concomitant oral corticosteroids dose, $\mathrm{mg}$ (daily) & $3.2(1.7)$ \\
\hline $\begin{array}{l}\text { Anti-cyclic citrullinated peptide (ACCP), Unit } \\
\text { ACCP positive, } n(\%)\end{array}$ & $\begin{array}{c}286.6(206.4) \\
63(52.9)\end{array}$ \\
\hline Rheumatoid factor (RF), KU/L & $139.5(395.4)$ \\
\hline RF positive, $n(\%)$ & $90(76.3)$ \\
\hline C-reactive protein (CRP), mg/L & $5.3(28.0)$ \\
\hline Erythrocyte sedimentation rate (ESR), $\mathrm{mm} / \mathrm{hr}$ & $11.4(8.4)$ \\
\hline Tender joint count (TJC) 68 & $0.3(0.6)$ \\
\hline Swollen joint count (SJC) 66 & $0.1(0.3)$ \\
\hline DAS28 (ESR) & $1.7(0.6)$ \\
\hline Clinical Disease Activity Index (CDAl) & $1.3(1.4)$ \\
\hline Simplified Disease Activity Index (SDAl) & $1.8(3.0)$ \\
\hline Patient's Global Assessment of Disease Activity -VAS, $0-100 \mathrm{~mm}$ & $6.4(8.9)$ \\
\hline Physician's Global Assessment of Disease Activity - VAS, $0-100 \mathrm{~mm}$ & $3.7(5.0)$ \\
\hline Pain-VAS, 0-100 mm & $8.5(11.5)$ \\
\hline HAQ-DI & $0.3(0.4)$ \\
\hline SF-36 MCS & $54.4(7.7)$ \\
\hline SF-36 PCS & $50.1(7.8)$ \\
\hline \multicolumn{2}{|l|}{ MRI OMERACT scores } \\
\hline Synovitis, Range 0-24 & $3.5(3.1)$ \\
\hline Osteitis, Range 0-75 & $1.0(2.0)$ \\
\hline Tenosynovitis, Range 0-30 & $2.7(2.7)$ \\
\hline Erosion, Range 0-250 & $21.4(26.9)$ \\
\hline
\end{tabular}

Conclusions: Pts with long-standing RA randomised to the tapering phase of the PREDICTRA study based on sustained DAS28-based clinical remission on prior standard dose ADA therapy showed very low levels of clinical disease activity and normal physical function. This concurred with low MRI inflammation scores, especially for osteitis and tenosynovitis, the latter pathology being reported for the first time in RA clinical remission pts.

Acknowledgements: AbbVie: study sponsor, study design, data collection, analysis, interpretation, writing, reviewing, and approval of the final version. Statistical support: Liang Chen; Med Writing Support: Siddharth Mukherjee, PhD, both from Abbvie.

Disclosure of Interest: P. Emery Grant/research support from: AbbVie, BristolMyers Squibb, Lilly, Merck, Novartis, Pfizer, Roche, Sandoz, and UCB, G. Burmester Grant/research support from: AbbVie, Bristol-Myers Squibb, Lilly, MSD, Novartis, Pfizer, Roche, Sandoz, and UCB, E. Naredo Consultant for: AbbVie, Roche, Bristol-Myers Squibb, Pfizer, UCB, Lilly, Novartis, Janssen, and Celgene $\mathrm{GmbH}$, I. Lagunes Shareholder of: Abbvie, Employee of: Abbvie, Y. Zhang Shareholder of: Abbvie, Employee of: Abbvie, X. Wang Shareholder of: Abbvie, Employee of: Abbvie, M. Hojnik Shareholder of: Abbvie, Employee of: Abbvie, P Conaghan Consultant for: AbbVie, Bristol-Myers Squibb, Lilly, Novartis, Pfizer, and Roche

DOI: 10.1136/annrheumdis-2018-eular.4804

\section{THU0125 PREVENTION OF THE PROGRESSIVE BIOCHEMICAL CARTILAGE DESTRUCTION UNDER METHOTREXATE THERAPY IN EARLY RHEUMATOID ARTHRITIS}

P. Sewerin ${ }^{1}$, A. Müller-Lutz ${ }^{2}$, S. Odendahl ${ }^{2}$, M. Eichner ${ }^{2}$, M. Schneider ${ }^{1}$, B. Ostendorf ${ }^{1}$, C. Schleich ${ }^{2} .{ }^{1}$ Department for Rheumatology, University Hospital Duesseldorf, ${ }^{2}$ Department of Diagnostic and Interventional, Radiology, HeinrichHeine University, Düsseldorf, Germany

Background: Can methotrexate (MTX) stop cartilage loss measured by Delayed gadolinium-enhanced MRI of the cartilage (dGEMRIC) in patients with early rheumatoid arthritis (eRA)?

Objectives: Objective of the study was to investigate biochemical cartilage composition under MTX therapy and to intra-individually assess the impact of inflammation severity on cartilage composition by using dGEMRIC MRI in patients with eRA

Methods: dGEMRIC of MCP joints of the index and middle finger of 28 patients from the AthroMark cohort were examined prior to MTX-therapy as well as after 3 and 6 month. OMERACT RA MRI score and clinical parameters (CRP and DAS28) were registered at any time point. Each patient's second and third MCP joints were dichotomized into the joint with more severe synovitis versus the joint with less severe synovitis according to the RAMRIS synovitis subscore.

Results: MCP joints with more severe synovitis ('bad joints') demonstrated significantly lower dGEMRIC values compared to MCP joints with less severe synovitis ('good joints') at time-points 0 and 3 months ( $p=0.002 ; p=0.019$, respectively). After 6 months of MTX therapy no significant difference of dGEMRIC index was found between good and bad joint $(p=0.086)$.

Conclusions: Under MTX therapy, biochemical cartilage integrity remains stable; no further cartilage destruction occurred if patients are treated early in the course of the disease. In addition, six months of MTX therapy triggered an alignment of
dGEMRIC index of MCP joints with initially severe synovitis and less severe synovitis in an intra-individual assessment. This underlines the importance of an early treatment in eRA to reduce further cartilage damage of the inflamed joints.

Acknowledgements: Funding: The ArthroMark project was founded by the Bundesministerium für Bildung und Forschung(BMBF) grant number FKZ 01EC1009A

Disclosure of Interest: None declared

DOI: 10.1136/annrheumdis-2018-eular.3536

\section{THU0126 IMPACT OF RESIDENTIAL AREA ON THE PROFILE OF RHEUMATOID ARTHRITIS PATIENTS INITIATING THEIR FIRST BIOLOGIC DMARD: RESULTS FROM THE ONTARIO BEST PRACTICES RESEARCH INITIATIVE (OBRI)}

R. Joshi ${ }^{1}$, M. Movahedi ${ }^{2,3}$, E. Rampakakis ${ }^{2}$, C. Thorne ${ }^{4}$, A. Cesta ${ }^{3}$, J.S. Sampalis ${ }^{5}$, C. Bombardier ${ }^{3,6,7}$, on behalf of Other OBRI Investigators. ${ }^{1}$ William Osler Health System, Brampton Civic Hospital, Brampton; ${ }^{2}$ JSS Medical Research, St-LaurentQC; ${ }^{3}$ Ontario Best Practices Research Initiative, Toronro General Research Insititute, University Health Network, Toronto; ${ }^{4}$ Southlake Regional Health Centre, Newmarket; ${ }^{5}$ McGill University, Montreal-QC; ${ }^{6}$ Department of Medicine (DOM) and Institute of Health Policy, Management, and Evaluation (IHPME), University of Toronto; ' Division of Rheumatology, Mount Sinai Hospital, Toronto, Canada

Background: Access to care and management of Rheumatoid Arthritis (RA) patients may differ based on residential area which, in turn, can affect the realworld effectiveness of anti-rheumatic medications.

Objectives: We aimed to describe differences in the profile of patients initiating their first biologic disease modifying antirheumatic drug (bDMARD) based on their residence in urban vs. rural areas.

Methods: RA patients enrolled in the OBRI initiating their first bDMARD within 30 days prior to or anytime following enrolment were included in the analysis. Patients excluded if they had less than 2 years of follow-up and less than 2 visits during this period of time. Patients characteristics included sociodemographics (age, gender, race, education level, marital status, smoking status, annual household income, health insurance coverage), disease duration, disease severity parameters (Disease Activity Score (DAS), Clinical Disease Activity Index (CDAI), Swollen and Tender Joints (SJC28, TJC28), Physician Global Assessment (PhGA), Patient Global Assessment (PGA), Health Assessment Questionnaire Disability Index (HAQ-DI), presence of erosion), bDMARD type, and concomitant anti-rheumatic medications including conventional synthetic disease modifying antirheumatic drug (csDMARDs), non-steroidal anti-inflammatory drugs (NSAIDs), and oral steroids.

Results: A total of 629 RA patients were included of whom $522(83 \%)$ resided in urban areas and $107(17 \%)$ in rural areas. Other than marital status (urban vs rural: $64.6 \%$ vs. $82.2 \%$ married; $p<0.001$ ) and race (urban vs. rural: $78.0 \%$ vs. $95.3 \%$ Caucasian; $p=0.001$ ) no significant differences in sociodemographics were observed between groups. However, patients from urban areas were less likely to have an erosion ( $46.6 \%$ vs. $50.5 \%$; $p=0.23)$, had lower TJC28 (7.2 vs. 7.9 $\mathrm{p}=0.43$ ), and lower SJC28 (6.6 vs. $7.1 ; \mathrm{p}=0.42)$ at bDMARD initiation. Type of bDMARD (anti-TNF vs. other mechanism of action) was comparable between groups $(87.9 \%$ on anti-TNF) as was concomitant treatment with csDMARDs (84.9\% on csDMARDs), and NSAIDs (19.6\% on NSAIDs). Concomitant use of oral steroids was significantly lower in patients from urban areas $(21.5 \%$ vs $29.9 \% ; p=0.04$ )

Conclusions: Important differences may exist in the profiles of RA patients initiating their first bDMARD, and residing in rural versus urban areas. The implications on treatment outcomes should be assessed.

Disclosure of Interest: R. Joshi Grant/research support from: OBRI was funded by peer reviewed grants from CIHR (Canadian Institute for Health Research), Ontario Ministry of Health and Long-Term Care (MOHLTC), Canadian Arthritis Network (CAN) and unrestricted grants from: Abbvie, Amgen, Celgene, Hospira Janssen, Lilly, Merck, Novartis, Pfizer, Roche, Sanofi, and UCB, M. Movahed Employee of: OBRI, E. Rampakakis Employee of: JSS Medical Research, C Thorne Grant/research support from: OBRI was funded by peer reviewed grants from CIHR (Canadian Institute for Health Research), Ontario Ministry of Health and Long-Term Care (MOHLTC), Canadian Arthritis Network (CAN) and unre stricted grants from: Abbvie, Amgen, Celgene, Hospira, Janssen, Lilly, Merck Novartis, Pfizer, Roche, Sanofi, and UCB, A. Cesta Employee of: OBRI, J. Sampalis: None declared, C. Bombardier Grant/research support from: OBRI was funded by peer reviewed grants from $\mathrm{CIHR}$ (Canadian Institute for Health Research), Ontario Ministry of Health and Long-Term Care (MOHLTC), Canadian Arthritis Network (CAN) and unrestricted grants from: Abbvie, Amgen, Celgene Hospira, Janssen, Lilly, Merck, Novartis, Pfizer, Roche, Sanofi, and UCB, Consultant for: Canada Research Chair in Knowledge Transfer for Musculoskeletal Care and a Pfizer Research Chair in Rheumatology DOI: 10.1136/annrheumdis-2018-eular.2194 